\title{
Design and expression of a retro doublet of cecropin with enhanced activity
}

\author{
Mauricio Díaz \\ Laboratorio de Genética e Inmunología Molecular \\ Instituto de Biología \\ Pontificia Universidad Católica de Valparaíso \\ Av. Brasil 2950, Valparaíso, Chile \\ Tel: 5632273119 \\ Fax: 5632596703 \\ E-mail: mauricio_diazruiz@yahoo.com \\ Gloria Arenas \\ Laboratorio de Genética e Inmunología Molecular \\ Instituto de Biología \\ Pontificia Universidad Católica de Valparaíso \\ Av. Brasil 2950, Valparaíso, Chile \\ Tel: 5632273117 \\ Fax: 5632596703 \\ E-mail: garenas@ucv.cl \\ Sergio H. Marshall* \\ Laboratorio de Genética e Inmunología Molecular \\ Instituto de Biología \\ Pontificia Universidad Católica de Valparaíso \\ Av. Brasil 2950, Valparaíso, Chile \\ Tel: 5632273119 \\ Fax: 5632596703 \\ E-mail:smarshal@ucv.cl
}

Financial support: This work was supported by the Copec-UC foundation and MECESUP.

Keywords: antimicrobial peptides, Escherichia coli, expression.

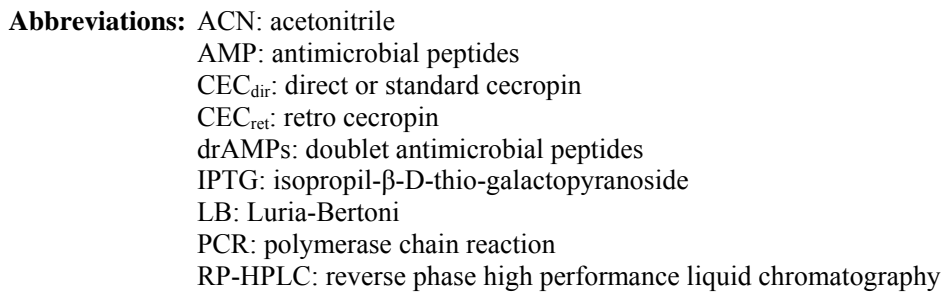

Novel doublet molecules of cecropin A from Drosophila melanogaster were designed and constructed combining the regular $\left(C E C_{\text {dir }}\right)$ with the inverted $\left(C E C_{\text {ret }}\right)$ coding sequence of the standard $\mathrm{CEC} A 1$ gene resulting in the following configurations: $\mathrm{CEC}_{\text {dir }}-\mathrm{CEC}_{\text {ret }}$ and $\mathrm{CEC}_{\text {ret }^{-}}$ $\mathrm{CEC}_{\text {dir }}$ - These two recombinant molecules were generated using a three-primer driven PCR reaction yielding composite single functional aminoacidic molecules with the coding sequences of $\mathrm{CEC}_{\mathrm{dir}}$ linked in frame with the coding sequence of $\mathrm{CEC}_{\text {ret }}$ and vice versa. In order to obtain these constructions, a retropeptide DNA-coding sequence was chemically synthesized to match the expected polarity of the newly generated $\mathrm{CEC}_{\text {ret }}$ sequence. Both doublet antimicrobial peptides (drAMPs) were cloned in the T7 promoter driven expression plasmid pET27b+ and expressed in $E$. coli BL21 without any fusion protein. Only the former recombinant peptide was expressed and purified from cell extracts and its specific activity against two different bacteria showed to be higher than those displayed by their monomer parental counterparts.

The discovery of natural peptides possessing a broad range of antimicrobial activities, synergy with conventional antibiotics and rapid killing action, has drawn attention as potential therapeutics (Zasloff, 2002). However, up to now the classical way to have access to these molecules has been their isolation from host organisms, which requires large amount of material with very low yields of functional peptides (Mercado et al. 2005). Other alternatives explored

*Corresponding author 

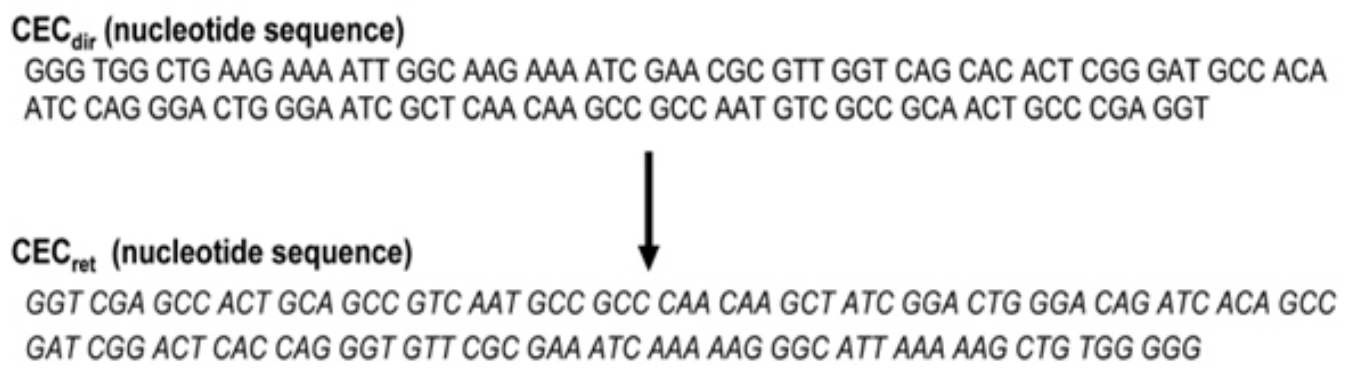

Figure 1. Inverted peptide-coding sequence synthesis design. Nucleotide and amino acid sequence of $\mathrm{CEC}_{\text {dir }}$ and $\mathrm{CEC}_{\text {ret. }}$

have been their chemical synthesis (Andreu et al. 1983) or their expression in heterologous systems following their cloning from origins (Piers et al. 1993; Zhang et al. 1998).

Most antimicrobial peptides (AMPs) act by penetrating bacterial membranes and promoting cell lysis, mechanism of action which is known to be critically dependent on their cationic and amphipathic nature (Yount and Yeaman, 2005). It has also been suggested that in some cases above a sufficiently high concentration of adsorbed peptides the mechanism depends on a peptide dimerization or oligomerization while they interact with the membrane of bacteria, which in turns results in, pore formation (Zemel et al. 2005). Studies using cross-linked disulfide-dimerized melittin and magainin analogssupport the idea that an interfacially adsorbed, self-associated dimer acts as a precursor or a meta-stable intermediate in the poreformation mechanism (Hristova et al. 2001; Dempsey et al. 2003). The spontaneous formation of disulphide-linked dimers or the engineering of dimers through crosslinking (Tencza et al. 1999; Dempsey et al. 2003) showed enhanced membrane permeabilization activity compared with the corresponding monomer, especially at low concentrations, where pore formation by the dimerized peptide occurs well below the monomers threshold concentration. It was suggested that membrane perturbation resulting from the formation of the peptide dimer is the essential event that triggers the change in peptide orientation and the formation of a pore (Hristova et al. 2001). Evidence also shows the existence of natural homo and heterodimers like distinctin from the frog $P$. distincta (Batista et al. 2001) and cryptdin-related sequence peptides in mouse intestinal tissue (Hornef et al. 2004). On the other hand, it has also been observed that a mixture of AMP classes do interact with each other in a synergic way enhancing their specific activity (Luders et al. 2003). Cecropins are linear peptides, isolated initially from insects, which present a strongly basic $\mathrm{NH}_{2}$ terminal region, enriched in lysine, and a large $\mathrm{COOH}$-terminal hydrophobic region (Holak et al. 1988; Boman, 1991). Their basal structure is alpha-helix and contains a strongly cationic region that permits interaction with the microorganism membrane and a large hydrophobic tail that induces the microbial lysis by alteration of the permeability of the membrane (Durell et al. 1992; Silvestro et al. 1997). Cecropin A from Drosophila melanogaster is a polycationic peptide that is active against a wide range of both Gram-positive and especially over Gram negative bacteria (Zasloff, 2002; Boman, 1998). Studies on molecular evolution of cecropins (Ramos-Onsins and Aguadé, 1998) demonstrated the importance of this multigene family in different species of invertebrates. Based upon these facts we designed and constructed a number of doublets of cecropin hoping to achieve, in a single molecule, the best efficiency of their parental counterparts and their recombinant expression in E. coli, considering that knowledge regarding the relationship between peptide structure and function as well as their mechanism of action is being applied in the design of antimicrobial peptide variants as potential novel therapeutic agents (Jenssen et al. 2006).

\section{MATERIALS AND METHODS}

\section{Bacterial strains, plasmids and growth conditions}

The pET27b+ (Novagen) vector was used for the expression of doublets $\mathrm{CEC}_{\mathrm{dir}}-\mathrm{CEC}_{\mathrm{ret}}, \mathrm{CEC}_{\mathrm{ret}}-\mathrm{CEC}_{\mathrm{dir}}$, as well as monomers $\mathrm{CEC}_{\mathrm{ret}}$ and $\mathrm{CEC}_{\mathrm{dir}}$. In these plasmids transcription of genes is controlled by the isopropil- $\beta$-Dthio-galactopyranoside (IPTG)-inducible T7/Lac promoter. 
E. coli TOP10 (Invitrogen) was routinely used as the host for propagation and maintenance. E. coli BL21(DE3) "codon plus" (Stratagene) was used as the host strain for protein expression. E. coli strains were grown at $37^{\circ} \mathrm{C}$ in Luria-Bertoni (LB) broth or agar, and $50 \mu \mathrm{g} / \mathrm{ml}$ of Chloramphenicol and $75 \mu \mathrm{g} / \mathrm{ml}$ of Streptomycin was added to the media for strain BL21(DE3). Kanamycin $(50 \mu \mathrm{g} / \mathrm{ml})$ was added to the media when TOP10 and BL21(DE3) were transformed with the expression plasmids. Pathogenic bacterial strains Vibrio anguillarum and Vibrio ordalii were grown at $26^{\circ} \mathrm{C}$ in Trypticase Soy Broth (TSB) and peptone$\mathrm{NaCl}$ (PSB) respectively.

\section{Construction of $\mathrm{CEC}_{\text {ret }}, \mathrm{CEC}_{\text {dir- }}-\mathrm{CEC}_{\text {ret }}$ and $\mathrm{CEC}_{\text {ret- }}$ CEC $_{\text {dir }}$ expression plasmids}

Previous two doublet constructions, a retropeptide-coding sequence of Cecropin A was designed to match the expected polarity for each coding triplets yielding the novel $\mathrm{CEC}_{\text {ret }}$ gene and was later synthesized by GenScript. The resulting "retropeptide" is made up of L-amino acids in which the amino acid residues are assembled in opposite direction to the native peptide (Merrifield et al. 1995). Doublets with the configurations [(NH2)headtail $(\mathrm{COOH})] \mathbf{\nabla}[(\mathrm{COOH})$ tail-head(NH2) $]$ like $\mathrm{CEC}_{\text {dir- }}-\mathrm{CEC}_{\text {ret }}$ and $\quad[(\mathrm{COOH})$ tail-head(NH2) $] \mathbf{\nabla}[(\mathrm{NH} 2)$ head-tail $(\mathrm{COOH})]$ like $\mathrm{CEC}_{\text {ret }}-\mathrm{CEC}_{\text {dir }}$ were then generated. Each doublet correspond to a single peptidic molecule representing the coding sequence of the original monomer CEC linked in tandem with its inverted coding sequence resulting in an enantiomer molecule at the amino acid level. The sequences of the mature peptides $\mathrm{CEC}_{\mathrm{dir}}$ and $\mathrm{CEC}_{\mathrm{ret}}$ and its coding sequences are shown in Figure 1. A DNA fragment encoding the mature domain of Cecropin A was obtained by PCR amplification of pBSCecA DNA, that carries the standard CEC A1 gene $\left(\mathrm{CEC}_{\mathrm{dir}}\right)$ used in this study (a kind gift from Dr. Dan Hultmark). The sequence of the 5 ' primer used for amplification (5'GGGTGGCTGAAGAAAATTG-3') corresponds to codons $\mathrm{Gly}^{+1}$ to $\mathrm{Ile}^{+6}$. The $3^{\text {' }}$ primer (5'ACCTCGGGCAGTTGCGGCG-3') is complementary to codons $\mathrm{Ala}^{+35}$ to $\mathrm{Gly}^{+40}$ (without stop codon). A DNA fragment encoding the mature domain of retro-cecropin A was obtained by PCR amplification of pUC57RET DNA, that carries the retro CEC A1 gene $\left(\mathrm{CEC}_{\mathrm{ret}}\right)$ (obtained from GenScript), using the 5' primer (5'GGTCGAGCCACTGCAGCCG-3') and 3' primer (5'CCCCCACAGCTTTTTAATG-3'). PCR was performed under the following conditions: incubation at $94^{\circ} \mathrm{C}$ for 10 min, 30 cycles incubation at $94^{\circ} \mathrm{C}$ for $30 \mathrm{sec}, 55^{\circ} \mathrm{C}$ for 30 a

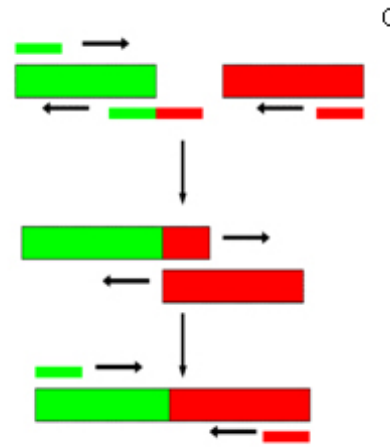

b

GGG TGG CTG AAG AAA ATT GGC AAG AAA ATC GAA CGC GTT GGT CAG CAC ACT CGG GAT GCC ACA ATC CAG GGA CTG GGA ATC GCT CAA CAA GCC GCC AAT GTC GCC GCAACT GCCCGA GGT GGT CGA GCCACT GCA GCC GTC AAT GCC GCC CAA CAA GCT ATC GGA CTG GGA CAG ATC ACA GCC GAT CGG ACT CAC CAG GGT GTT CGC GAA ATC AAA AAG GGC ATT AAAAAGCTG TGG GGG

GGT CGA GCC ACT GCA GCC GTC AAT GCC GCC CAA CAA GCT ATC GGA CTG GGA CAG ATC ACA GCC GAT CGG ACT CAC CAG GGT GTT CGC GAAATC AAA AAG GGC ATT AAA AAG CTG TGG GGG GGG TGG CTG AAG AAA ATT GGC AAG AAA ATC GAA CGC GTT GGT CAG CAC ACT CGG GAT GCC ACAATC CAG GGACTG GGAATC GCT CAA CAAGCC GCC AAT GTC GCC GCAACT GCC CGAGGT

Figure 2. Doublets design and sequence.

(a) Three-primer driven PCR reaction with hybrid primer (red-green) and flanking primers (red or green). DNA templates are in red and green boxes.

(b) $\mathrm{CEC}_{\text {dir }}-\mathrm{CEC}_{\text {ret }}$ (top panel) and $\mathrm{CEC}_{\text {ret }}-\mathrm{CEC}_{\text {dir }}$ (bottom panel) doublets construction design: using $\mathrm{CEC}_{\text {dir }}$ (in black) and $\mathrm{CEC}_{\text {ret }}$ (in blue) as templates. Sequences of hybrid primers used for fusion are underlined in red. Initiation codon ATG is omitted from scheme.

(c) A scheme of the amino acid sequence of doublets of cecropin $\mathrm{CEC}_{\text {dir }}-\mathrm{CEC}_{\text {ret }}$ (top panel) and $\mathrm{CEC}_{\text {ret }}-\mathrm{CEC}$ dir (bottom panel) from amino terminal to carboxi terminal orientation. Positively charged amino acids are marked by plus symbols (+). Initial methionine amino acid is omitted from scheme. 
sec, $72^{\circ} \mathrm{C}$ for $45 \mathrm{sec}$, and final incubation at $72^{\circ} \mathrm{C}$ for 10 min. The PCR product of $\mathrm{CEC}_{\text {dir }}$ and $\mathrm{CEC}_{\text {ret }}$ were analyzed by agarose gel electrophoresis (2\%) and purified using Rapid Gel extraction systems (Marligen). The resulting fragments were used as templates for a three-primer driven PCR reaction, where the coding sequence of $\mathrm{CEC}_{\mathrm{dir}}$ was linked in frame with the coding sequence of $\mathrm{CEC}_{\text {ret }}$ in the case of $\mathrm{CEC}_{\mathrm{dir}}-\mathrm{CEC}_{\mathrm{ret}}$, and the coding sequence of $\mathrm{CEC}_{\mathrm{ret}}$ was linked in frame with the coding sequence of $\mathrm{CEC}_{\mathrm{dir}}$ in the case of $\mathrm{CEC}_{\mathrm{ret}}-\mathrm{CEC}_{\mathrm{dir}}$. For the construction of $\mathrm{CEC}_{\mathrm{dir}}{ }^{-}$ $\mathrm{CEC}_{\text {ret }}$ PCR amplification was done with a hybrid primer complementary to the last 7 codons of CEC and the first 7 codons of $\mathrm{CEC}_{\text {ret }}$ (5'GACGGCTGCAGTGGCTCGACCACCTCGGGCAGTTG CGGCGAC-3'), as well as the $5^{\prime}$, primer (5'GAGATATACATATGGGGTGGCTGAAGAAAA-3') corresponding to codons $\mathrm{Gly}^{+1}$ to $\mathrm{Il}^{+6}$ of $\mathrm{CEC}_{\mathrm{dir}}$, and the restriction site for NdeI, and the $3^{\prime}$, primer (5'GCGGATCCTCATCACCCCCACAGCTTTTTAA-3') complementary to codons $\mathrm{Ile}^{+35}$ to $\mathrm{Gly}^{+40}$ of $\mathrm{CEC}_{\text {ret, }}$, with a stop codon and restriction site for BamHI. The same procedure was used for the construction of $\mathrm{CEC}_{\mathrm{ret}}-\mathrm{CEC}_{\mathrm{dir}}$ using a hybrid primer complementary to the last 7 codons of $\mathrm{CEC}_{\text {ret }}$ and the first 7 codons of $\mathrm{CEC}_{\text {dir }}$ (5'GCCAATTTTCTTCAGCCACCCCCCCCACAGCTTTTT AATGCC-3'), as well as the 5' primer (5'GAGATATACATATGGGTCGAGCCACTGCAG-3') corresponding to codons $\mathrm{Gly}^{+1}$ to $\mathrm{Ala}^{+6}$ of $\mathrm{CEC}_{\mathrm{ret}}$, and the restriction site for NdeI, and the $3^{\prime}$, primer (5'GCGGATCCTCATCAACCTCGGGCAGTTGCGG-3') complementary to codons $\mathrm{Ala}^{+35}$ to $\mathrm{Gly}^{+40}$ of $\mathrm{CEC}_{\text {dir, }}$, with a stop codon and restriction site for BamHI. PCR

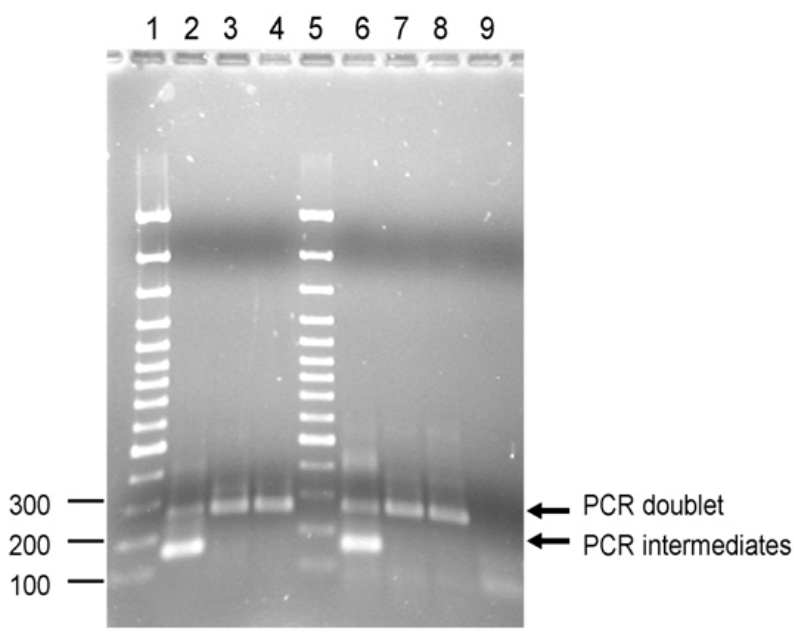

Figure 3. PCR profile of doublets. PCR of CECret-CECdir (left) and CECret-CECdir (right) generated by three-primer driven PCR reaction at different $(10,1,0.1 \mu \mathrm{M})$ hybrid primer concentrations resolved through agarose $(2 \%) \mathrm{gel}$ electrophoresis. Lanes1,5: Molecular Weight Ladder (Winkler Ltda, Santiago, Chile), Lanes 2-4: $\mathrm{CEC}_{\text {dir }}-\mathrm{CEC}_{\text {ret }}$ at 10, 1 and 0.1 $\mu \mathrm{M}$ hybrid primer ratio, Lanes 6-8 $\mathrm{CEC}_{\text {ret }}-\mathrm{CEC}_{\text {dir }}$ at 10,1 and 0.1 $\mu \mathrm{M}$ hybrid primer ratio, Lane 9: negative control. The faint band right below $100 \mathrm{bp}$ corresponds to primer dimers. amplifications were performed under the following conditions: incubation at $94^{\circ} \mathrm{C}$ for $10 \mathrm{~min}, 30$ cycles incubation at $94^{\circ} \mathrm{C}$ for $30 \mathrm{sec}, 65^{\circ} \mathrm{C}$ for $30 \mathrm{sec}, 72^{\circ} \mathrm{C}$ for 45 $\mathrm{sec}$, and final incubation at $72^{\circ} \mathrm{C}$ for $10 \mathrm{~min}$, using different concentrations of the hybrid primer and $1 \mathrm{U}$ of Taq DNA polymerase (Invitrogen, Brazil). The resulting doublet fragments and the corresponding monomers were analyzed by agarose gel electrophoresis $(2 \%)$ and precipitated by standard methods (Sambrook et al. 1989) and subject to restriction digestion with $\mathrm{NdeI}$ and BamHI. The resulting fragments were precipitated again and ligated between the NdeI and BamHI restriction sites within the multiple cloning site of pET27b+. Ligation mixtures were used to transform competent TOP10 cells (Invitrogen). Plasmid DNA was isolated by miniprep kit (Qiagen). Plasmids were sequenced to confirm the identity of the constructs. Expression plasmids were subsequently used to transform competent BL21(DE3) cells (Stratagene).

\section{Expression and purification of doublets}

E. coli BL21(DE3) $\mathrm{pET} / \mathrm{CEC}_{\mathrm{dir}}-\mathrm{CEC}_{\mathrm{ret}}$ and $\mathrm{pET} / \mathrm{CEC}_{\mathrm{ret}^{-}}$ $\mathrm{CEC}_{\mathrm{dir}}$ and the corresponding monomers $\mathrm{pET} / \mathrm{CEC}_{\mathrm{dir}}$ and $\mathrm{pET} / \mathrm{CEC}_{\mathrm{ret}}$ transformation single colonies were used to inoculate $10 \mathrm{ml} \mathrm{LB}$ Broth supplemented with antibiotics at $37^{\circ} \mathrm{C}$ and grown overnight. Next morning $10 \mathrm{ml}$ of each culture $(20 \mu \mathrm{l} / \mathrm{ml} \mathrm{LB})$ were added to $500 \mathrm{ml} \mathrm{LB}$ Broth without antibiotic selection and incubated for $2 \mathrm{hrs}$ until the $\mathrm{A}_{600}$ reached 0.3. After collection of preinduction samples, IPTG was added to the cultures to a final concentration of $0.5 \mathrm{mM}$ and incubated for up to $4 \mathrm{hrs}$ before sampling. Samples were separated by centrifugation at $7,000 \mathrm{~g} \mathrm{x} 10$ min at $4^{\circ} \mathrm{C}$ into cell pellet and supernatant fractions. Samples of cell pellets solubilized directly in sample loading buffer containing sodium dodecyl sulphate (SDS) were analyzed on 18\% Tris-tricine/Urea-polyacrylamide gels (Schagger and von Jagow, 1987) and stained with R250 Coomassie Blue. Samples were also subjected to peptide extraction. Cell pellets were treated with lyses buffer (Tris-HCl $50 \mathrm{mM}, \mathrm{NaCl} 100 \mathrm{mM}, \mathrm{pH}$ 8), lysozyme $(100 \mu \mathrm{g} / \mathrm{ml})$ and vortexed, incubated at room temperature for $30 \mathrm{~min}$, subjected to ultra-sonication on ice $(3 \times 20 \mathrm{sec})$ and centrifugation at $11000 \mathrm{~g} \times 30 \mathrm{~min}$ at $4^{\circ} \mathrm{C}$ and supernatant fractions were recovered. Samples were purified by hydrophobic interaction chromatography in Sep-Pak C-18® columns pre-equilibrated with acidified water $(0.05 \%$ trifluoroacetic acid in ultrapure water UPW) and washed with acidified water and eluted with 5 and $80 \%$ acetonitrile (ACN). Eluted fractions were lyophilized and reconstituted in UPW. Total protein concentration was determined by bicinchoninic acid (BCA) protein assay (Pierce) (Smith et al. 1985).

\section{HPLC purification}

Purification was performed on a RP-HPLC model LaChrom D-7000 and was monitored by UV absorbance at $225 \mathrm{~nm}$. The $80 \%$ Sep-Pak eluate was loaded onto a Sephasil C-18 $(250 \times 4.1 \mathrm{~mm})$ column (LiChroCART). 
Table 1. Antimicrobial profile of $\mathrm{CEC}_{\text {dir- }}-\mathrm{CEC}_{\text {ret }}$ post HPLC fraction compared to $\mathrm{CEC}_{\text {dir }}$ and $\mathrm{CEC}_{\text {ret }}$ obtained by chemical synthesis.

\begin{tabular}{|c|c|c|c|c|}
\hline Bacterial strains & $\operatorname{MIC}(\mu \mathrm{M})$ & OD $620 \mathrm{~nm}$ (bacterial growth) & $\begin{array}{l}\text { SD } \\
\left(\sigma_{n-1}\right)\end{array}$ & $\begin{array}{l}\% \text { inhibition } \\
\text { (average) }\end{array}$ \\
\hline \multicolumn{5}{|c|}{ CEC $_{\text {dir- }}$ CEC $C_{\text {ret }}$} \\
\hline V. ordalii & 1.08 & $\begin{array}{c}0,04 ; \quad 0,036 ; \quad 0,038 \\
(C=0.298)\end{array}$ & 0,002 & 87,25 \\
\hline V. anguillarum & 1.08 & $\begin{array}{c}0,224 ; 0,233 ; 0,228 \\
(C=0.301)\end{array}$ & 0,005 & 25 \\
\hline \multicolumn{5}{|c|}{ CEC $_{\text {dir }}$} \\
\hline V. ordalii & 2.16 & $\begin{array}{c}0.042 ; 0.041 ; 0.038 \\
\quad(C=0.298)\end{array}$ & 0.002 & 87 \\
\hline V. anguillarum & 2.16 & $\begin{array}{c}0.458 ; 0.499 ; 0.478 \\
(C=0.301)\end{array}$ & 0.021 & $(-)^{a}$ \\
\hline \multicolumn{5}{|c|}{ CEC $_{\text {ret }}$} \\
\hline V. ordalii & 2.16 & $\begin{array}{l}0.441 ; 0.488 ; 0.438 \\
\quad(C=0.474)\end{array}$ & 0,0391 & $(-)^{a}$ \\
\hline V. anguillarum & 2.16 & $\begin{array}{c}0.293 ; 0.344 ; 0.319 \\
(C=0.169)\end{array}$ & 0,0255 & $(-)^{a}$ \\
\hline
\end{tabular}

${ }^{a}$ No activity over the strain.

OD indicates bacterial growth. Higher OD indicates less inhibition.

$\mathrm{C}$ indicates OD control without peptides.

Peptides were eluted with a linear gradient of acetonitrile (5-60\%) with acidified water $0.1 \%$ trifluoroacetic acid (TFA) over $90 \mathrm{~min}$ at a flow rate of $0.6 \mathrm{ml} / \mathrm{min}$. Fractions were collected every two minutes, lyophilized, reconstituted in UPW and frozen at $-20^{\circ} \mathrm{C}$ until antimicrobial activity assay. Post-HPLC fractions were analyzed on $18 \%$ Tris-tricine/Urea-polyacrylamide gels to confirm the identity of the peptide.

\section{Antimicrobial activity assay}

Antimicrobial activity of the peptides was monitored by liquid growth inhibition assay (Mitta et al. 1999). In microtiter plates $10 \mu \mathrm{l}$ of the samples with the peptide were incubated with $100 \mu \mathrm{l}$ of a suspension of bacteria in TBS [(Tris Borate Saline Buffer) for $V$. ordalii and $V$. anguillarum] at a starting optical density of $\mathrm{A}_{620}: 0.001$. Bacterial growth was assayed by measurement of optical density at $\mathrm{A}_{620}$ after a $24 \mathrm{hrs}$ incubation at $26^{\circ} \mathrm{C}$. Percentage growth inhibition was determined by subtracting bacterial growth values in the absence of peptides from that displayed by bacteria exposed to different concentrations of the peptide. As positive control an antibiotic was used to fully inhibit bacterial growth in the absence of added salt. As negative control samples of induced E. coli with plasmid without insert was used. Peptides were solubilized in ultra pure water.

The standard CEC A1 geneused in this study is GenBank accession no. X16972.

\section{RESULTS}

\section{Construction of gene $\mathrm{CEC}_{\text {ret }}$}

A retropeptide-coding sequence of mature Cecropin was designed and synthesized (GenScript) to match the expected polarity for each coding triplets $\mathrm{CEC}_{\text {ret }}$. Considering that a retro triplet-nucleotide sequence does not necessary code for a retro-aminoacid sequence, an adjustment was necessary at the nucleotide level (sequence not shown) in order to generate the expected inverted amino acid coding sequence of the gene (Figure 1). 


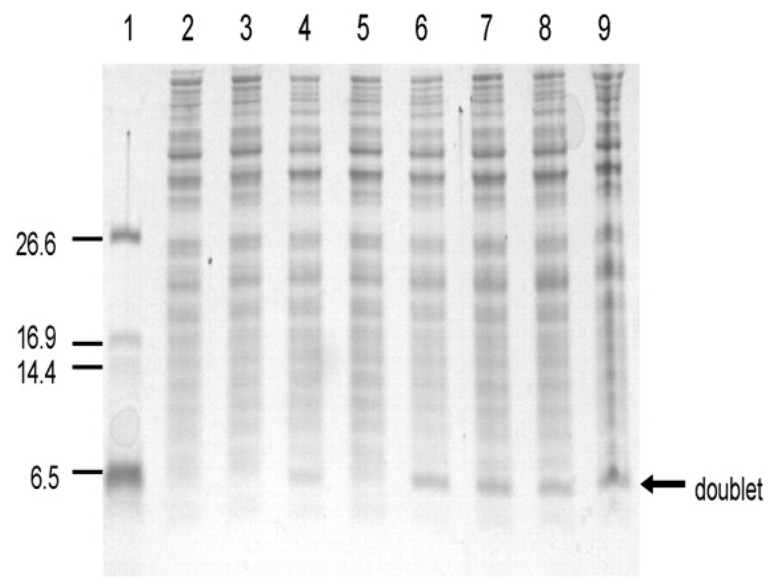

Figure 4. Expression profile of doublet. Expression of $\mathrm{CEC}_{\text {dir- }}$ $\mathrm{CEC}_{\text {ret }}$ from BL21/pET cells induced with IPTG, resolved through Tris-tricine / Urea (18\%) gel electrophoresis. Lane 1: Molecular Weight Ladder (Winkler Ltda, Santiago, Chile), Lane 2,3: Control (BL21 carrying pET CEC dir $-\mathrm{CEC}_{\text {ret }}$ without IPTG induction) at 37 and $26^{\circ} \mathrm{C} 6$ hrs incubation respectively, Lane 4,5: BL21 carrying pET $\mathrm{CEC}_{\text {dir }}-\mathrm{CEC}_{\text {ret }}$ at 37 and $26^{\circ} \mathrm{C}$ with $2 \mathrm{hrs}$ IPTG induction, Lane 6,7: BL21 carrying pET CEC dir $-\mathrm{CEC}_{\text {ret }}$ at 37 and $26^{\circ} \mathrm{C}$ with 4 hrs IPTG induction, Lane 8,9: BL21 carrying pET CEC dir $-\mathrm{CEC}_{\text {ret }}$ at 37 and $26^{\circ} \mathrm{C}$ with 6 hrs IPTG induction.

\section{Construction of doublets}

$\mathrm{CEC}_{\mathrm{dir}}-\mathrm{CEC}_{\mathrm{ret}}$ and $\mathrm{CEC}_{\mathrm{ret}}-\mathrm{CEC}_{\mathrm{dir}}$ were designed and constructed by means of a three-primer driven PCR reaction (Figure 2a and Figure 2b) in order to combine the orientation of the charged amino acids in the doublet molecules. In the case of $\mathrm{CEC}_{\mathrm{dir}}-\mathrm{CEC}_{\text {ret }}$ the coding sequence of $\mathrm{CEC}_{\mathrm{dir}}$ was linked in frame with the coding sequence of $\mathrm{CEC}_{\text {ret }}$ and the doublet peptide displays the positively charged amino acids to the extremes and the hydrophobic tails oriented towards the interior (Figure 2c). In the case of $\mathrm{CEC}_{\text {ret }}-\mathrm{CEC}_{\mathrm{dir}}$ the coding sequence of $\mathrm{CEC}_{\mathrm{ret}}$ was linked in frame with the coding sequence of $\mathrm{CEC}_{\mathrm{dir}}$ and the doublet peptide displays the positively charged amino acids to the interior and the hydrophobic tails oriented to the extremes (Figure 2c). The tandem doublet $\mathrm{CEC}_{\text {dir }^{-}}$ $\mathrm{CEC}_{\text {dir }}$ was not constructed based on previous information that it lacked antimicrobial activity (Martemyanov et al. 1997). Figure 3 confirms the construction of the two doublets. An amplification product of the desired size of the doublet coding sequences with their restriction sites (264 $\mathrm{bp)}$ is seen in lanes 3-4 and 7-8 for each corresponding doublet obtained when limiting the availability of the hybrid primer $(0.1 \mu \mathrm{M}$ ideal primer ratio). Also shown is the formation of PCR intermediates when there is no limitation in the availability of the hybrid primer (Lanes 2 and 6 , respectively). Once confirmed the expected size of $\mathrm{CEC}_{\mathrm{dir}}-\mathrm{CEC}_{\text {ret }}$ and $\mathrm{CEC}_{\mathrm{ret}}-\mathrm{CEC}_{\mathrm{dir}}$, the doublets and thecorresponding monomers $\mathrm{CEC}_{\mathrm{dir}}$ and $\mathrm{CEC}_{\text {ret }}$ sequences as controls were cloned in the $\mathrm{T} 7$ promoter driven expression plasmid pET27b+ where correct frame and sequence were confirmed by sequencing.

\section{Expression and purification of doublets}

Peptide expression was attained only with $\mathrm{CEC}_{\mathrm{dir}}-\mathrm{CEC}_{\text {ret }}$ doublet as shown in Figure 4. Samples were analyzed on polyacrylamide gels to allow visualization of peptides from crude cell extract. An expression product of approximately the expected size $(8540.9 \mathrm{Da})$ of the doublet $\mathrm{CEC}_{\mathrm{dir}}-\mathrm{CEC}_{\mathrm{ret}}$ was obtained for samples induced with IPTG, but was absent in the samples without IPTG induction. The monomers $\mathrm{CEC}_{\text {dir }}$ and $\mathrm{CEC}_{\mathrm{ret}}$ as the doublet $\mathrm{CEC}_{\mathrm{ret}}-\mathrm{CEC}_{\mathrm{dir}}$ were not expressed or have been degraded. Additional constructs of monomers and doublets cloned in frame with the pelB periplasmic signal peptide permitted the expression of $\mathrm{CEC}_{\mathrm{dir}}, \mathrm{CEC}_{\mathrm{ret}}$ and $\mathrm{CEC}_{\mathrm{dir}}-\mathrm{CEC}_{\text {ret }}$, but showed tenfold reduced activity compared to this construct (data not shown). The total amount of protein recovery from the supernatant of the $500 \mathrm{ml}$ cultures of $\mathrm{CEC}_{\mathrm{dir}}-\mathrm{CEC}_{\mathrm{ret}}$ post Sep-Pak fractions was $170 \mu \mathrm{g}$ present in the $80 \%$ ACN fraction. Subsequent data showed that the destination of expression product was primarily towards inclusion bodies.

\section{HPLC purification}

RP-HPLC of the $80 \%$ Sep-Pak eluate permitted the obtention of a chromatogram with one major peak showing the hydrophobic property of the peptide evident in the late retention time, where $\mathrm{CEC}_{\mathrm{dir}}-\mathrm{CEC}_{\text {ret }}$ was eluted at $47-48 \%$ ACN. This peak was analyzed on polyacrylamide gels to allow visualization of purified peptides, confirming the presence of the doublet (Figure 5) showing the same migration of induced cells (Figure 4). Mass spectrometry further confirmed the presence of the recombinant doublet.

\section{Antimicrobial activity assay}

Post HPLC purified fractions of $\mathrm{CEC}_{\mathrm{dir}}-\mathrm{CEC}_{\mathrm{ret}}$ were subject to antimicrobial activity assay performed in triplicates and compared with the monomers $\mathrm{CEC}_{\mathrm{dir}}$ and $\mathrm{CEC}_{\mathrm{ret}}$ obtained by chemical synthesis (a kind gift from Dr. Fanny Guzman). The antimicrobial activity of the doublet $\mathrm{CEC}_{\mathrm{dir}}{ }^{-}$ $\mathrm{CEC}_{\text {ret }}$ was found in the $80 \%$ ACN elution fractions with a retention time of $69.18 \mathrm{~min}$, and showed a two fold enhanced activity compared with its parental counterpart against Gram negative bacteria $V$. anguillarum and $V$. ordalii (Table 1).

\section{DISCUSSION}

This study shows a novel design of genetic constructions involving doublets of the AMP Cecropin A from Drosophila melanogaster coding sequences. The strategy involved the inversion of the amino acid coding sequence compared to its original form, with the purpose of enhancing their potential interaction with the membrane structure of bacterial pathogen based upon the synergistic activity displayed by dimeric and/or oligomeric forms of a given AMP. The constructs were restricted to only two doublet forms of $\mathrm{CEC}_{\mathrm{dir}}$ and its retro form $\mathrm{CEC}_{\mathrm{ret}}$ resulting in novel configurations $\mathrm{CEC}_{\mathrm{dir}}-\mathrm{CEC}_{\mathrm{ret}}$ and $\mathrm{CEC}_{\mathrm{ret}}-\mathrm{CEC}_{\mathrm{dir}}$. 


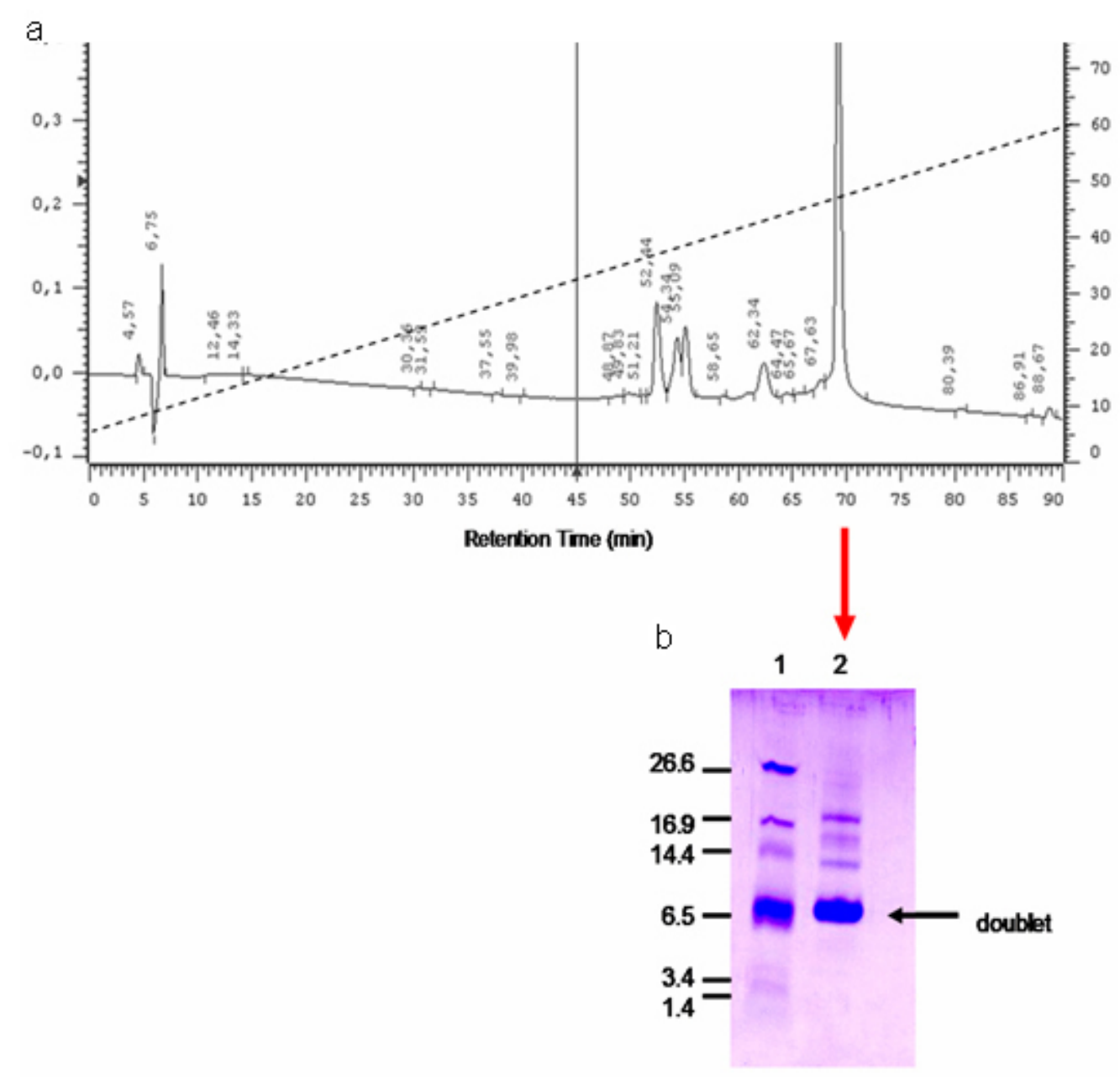

Figure 5. Purification of doublet by RP-HPLC.

(a) RP-HPLC elution profile of the $80 \%$ ACN post Sep-Pak C-18 with a gradient of $5-60 \%$ ACN.

(b) Protein profile resolved through Tris-tricine / Urea (18\%) gel electrophoresis Lane 1: Molecular Weight Standards (Bio-Rad, CA,

USA), Lane 2 eluate from chromatogram peak with a retention time of $69.18 \mathrm{~min}$ corresponding to the doublet $\mathrm{CEC}_{\text {dir }}-\mathrm{CEC}_{\text {ret. }}$.

We expected that the novel configuration could perhaps mimic eventual dimer formation of cecropin on the bacterial surface that could enhance its interaction or penetrating properties with the microbial membrane, affecting antimicrobial properties.

This is the first report of the generation of a doublet AMP without cross-linked disulfides bridges joining the monomers (Hristova et al. 2001; Dempsey et al. 2003) directly obtained by biosynthesis from cells and not by chemical synthesis (Merrifield et al. 1995). These constructs are also different from previous classic doublet construction of cecropin in tandem repeats $\left(\mathrm{CEC}_{\mathrm{dir}}-\mathrm{CEC}_{\mathrm{dir}}\right)$, obtained from a cell free transcription-translation system, that was not able to show antimicrobial activity (Martemyanov et al. 1997). The design and construction of the new doublets was not an easy task since ligation of two identical cecropin PCR amplification products could only generate a classic doublet in tandem $\left(\mathrm{CEC}_{\mathrm{dir}}-\mathrm{CEC}_{\mathrm{dir}}\right)$. The inversion of the $\mathrm{CEC}$ sequence does not give the direct inversion of the amino acid sequence due to genetic code degeneracy. Therefore we had to design and construct a new gene, representing the inverted amino acid sequence which we named $\mathrm{CEC}_{\mathrm{ret}}$. The construction of the "retrogene" provided significant information to sustain the idea of new constructions, since to our surprise, the retropeptide, which has the same amino acids than the standard peptide, was not at all functional, a situation that has a number of interpretations based upon reported analogue cases (Merrifield et al. 1995).

The enhanced antimicrobial activity displayed by the doublet cecropin $\left(\mathrm{CEC}_{\mathrm{dir}}-\mathrm{CEC}_{\mathrm{ret}}\right)$ is an intrinsic property of the new molecule, since $\mathrm{CEC}_{\mathrm{ret}}$ did not show any activity by itself and the one displayed by the monomer parental counterpart $\mathrm{CEC}_{\mathrm{dir}}$, is significantly lower. Enhanced activity by doublets of cecropin could maybe support some process of oligomerization or aggregation of this peptide in the bacterial membrane in a similar way that has been demonstrated with magainin (Dempsey et al. 2003; Zemel et al. 2005). 
This is one of the few cases in which an active peptide is obtained from bacteria without the use of protein fusions. In addition, this doublet form of cecropin showed enhanced expression and stability compared with the monomeric form. Only obtained associated with a signal sequence such as pelB (Piers et al. 1993; Skosyrev et al. 2003). Thus, this result opens a feasible alternative to commercial-scale synthesis of pure forms of selected antimicrobial peptides using recombinant DNA techniques.

The fact that we obtained efficient expression of the doublet $\mathrm{CEC}_{\mathrm{dir}}-\mathrm{CEC}_{\text {ret }}$, but not with the inverted form ofCEC $\mathrm{ret}-\mathrm{CEC}_{\mathrm{dir}}$ could perhaps be due to a required freedom of the hydrophobic tails that could react with the membranes of target microorganisms which in the inverted form are oriented towards the interior and thus not available.

In conclusion, these results show the viability in producing recombinant antimicrobial peptides in doublet form, without fusion proteins and without signal peptides. This design could show the way to generate novel doublet AMP with enhanced stability and activity. In this frame, new constructs involving the use of inducible self-cleavage activity of a protein splicing element (termed intein) are currently ongoing in our laboratory.

\section{ACKNOWLEDGMENTS}

We thank Paulina Schmitt and Dr. Luis Mercado for their invaluable help and expertise in purification and antimicrobial assays.

\section{REFERENCES}

ANDREU, D.; MERRIFIELD, R.B.; STEINER, H. and BOMAN, H.G. Solid-phase synthesis of cecropin A and related peptides. Proceedings of the National Academy of Sciences of the United States of America, November 1983, vol. 80 , no. 21 , p. 6475-6479.

BATISTA, C.V.; SCALONI, A.; RIGDEN, D.J.; SILVA, L.R.; RODRIGUES ROMERO, A.; DUKOR, R.; SEBBEN, A.; TALAMO, F. and BLOCH, C. A novel heterodimeric antimicrobial peptide from the tree-frog Phyllomedusa distincta. FEBS Letters, April 6 2001, vol. 494, no. 1-2, p. 85-89.

BOMAN, H.G. Antibacterial peptides: key components needed in immunity. Cell, April 19 1991, vol. 65, no. 2, p. 205-207.

BOMAN, H.G. Gene-encoded peptide antibiotics and the concept of innate immunity: an update review. Scandinavian Journal of Immunology, July 1998, vol. 48, no. 1, p. 15-25.

DEMPSEY, C.E.; UENO, S. and AVISON, M.B. Enhanced membrane permeabilization and antibacterial activity of a disulfide-dimerized magainin analogue. Biochemistry, January 21 2003, vol. 42, no. 2, p. 402-409.

DURELL, S.R.; RAGHUNATHAN, G. and GUY, H.R. Modeling the ion channel structure of cecropin. Biophysical Journal, December 1992, vol. 63, no. 6, p. 1623-1631.

HOLAK, T.A.; ENGSTROM, A.; KRAULIS, P.J.; LINDEBERG, G.; BENNICH, H.; JONES, T.A.; GRONENBORN, A.M. and CLORE, G.M. The solution conformation of the antibacterial peptide cecropin A: a nuclear magnetic resonance and dynamical simulated annealing study. Biochemistry, October 4 1988, vol. 27, no. 20, p. 7620-7629.

HORNEF, M.W.; PUTSEP, K.; KARLSSON, J.; REFAI, E. and ANDERSSON, M. Increased diversity of intestinal antimicrobial peptides by covalent dimer formation. Nature Immunology, August 2004, vol. 5, no. 8, p. 836-843.

HRISTOVA, K.; DEMPSEY, C.E. and WHITE, S.H. Structure, location, and lipid perturbations of melittin at the membrane interface. Biophysical Journal, February 2001, vol. 80 , no. 2, p. 801-811.

JENSSEN H.; HAMILL P. and HANCOCK R.E. Peptide antimicrobial agents. Clinical Microbiology Reviews, July 2006, vol. 19, no. 3, p. 491-511.

LUDERS, T.; BIRKEMO, G.A.; FIMLAND, G.; NISSENMEYER, J. and NES, I.F. Strong synergy between a eukaryotic antimicrobial peptide and bacteriocins from lactic acid bacteria. Applied and Environmental Microbiology, March 2003, vol. 69, no. 3, p. 1797-1799.

MARTEMYANOV, K.A.; SPIRIN, A.S. and GUDKOV, A.T. Direct expression of PCR products in a cell-free transcription/translation system: synthesis of antibacterial peptide cecropin. FEBS Letters, September 8 1997, vol. 414, no. 2, p. 268-270.

MERCADO, L.; SCHMITT, P.; MARSHALL, S. and ARENAS, G. Gill tissues of the mussel Mytilus edulis chilensis: A new source for antimicrobial peptides. Electronic Journal of Biotechnology [online]. December 15 2005, vol. 8, no. 3 Available from: http://www.ejbiotechnology.info/content/vol8/issue3/full/2/ index.html. ISSN 0717-3458.

MERRIFIELD, R.B.; JUVVADI, P.; ANDREU, D.; UBACH, J.; BOMAN, A. and BOMAN, H.G. Retro and retroenantio analogs of cecropin-melittin hybrids. Proceedings of the National Academy of Sciences of the United States of America, April 11 1995, vol. 92, no. 8, p. 3449-3453.

MITTA, G.; HUBERT, F.; NOEL, T. and ROCH, P. Myticin, a novel cysteine-rich antimicrobial peptide isolated from haemocytes and plasma of the mussel Mytilus 
galloprovincialis. European Journal of Biochemistry, October 1 1999, vol. 265, no. 1, p. 71-78.

PIERS, K.L.; BROWN, M.H. and HANCOCK, R.E. Recombinant DNA procedures for producing small antimicrobial cationic peptides in bacteria. Gene, November 30 1993, vol. 134, no. 1, p. 7-13.

RAMOS-ONSINS S. and AGUADÉ M. Molecular evolution of the Cecropin multigene family in Drosophila: functional genes vs. pseudogenes. Genetics, September 1998, vol. 150, no. 1, p. 157-171.

SAMBROOK, J.; FRITISCH, E.F. and MANIATIS, T. Molecular Cloning. A Laboratory Manual, second edition, Cold Spring Harbor, NY, Cold Spring Harbor Laboratory Press, 1989, 1659 p. ISBN: 0-87969-309-6.

SCHAGGER, H. and VON JAGOW, G. Tricine-sodium dodecyl sulfate-polyacrylamide gel electrophoresis for the separation of proteins in the range from 1 to $100 \mathrm{kDa}$. Analytical Biochemistry, November 1987, vol. 166, no. 2, p. $368-379$.

SILVESTRO, L.; GUPTA, K.; WEISER, J.N. and AXELSEN, P.H. The concentration-dependent membrane activity of cecropin A. Biochemistry, September 23 1997, vol. 36 , no. 38, p. 11452-11460.

SKOSYREV, V.S.; KULESSKIY, E.A.; YAKHNIN, A.V.; TEMIROV, Y.V. and VINOKUROV, L.M. Expression of the recombinant antibacterial peptide sarcotoxin IA in Escherichia coli cells. Protein Expression and Purification, April 2003, vol. 28, no. 2, p. 350-356.

SMITH, P.K.; KROHN, R.I.; HERMANSON, G.T.; MALLIA, A.K.; GARTNER, F.H.; PROVENZANO, M.D.; FUJIMOTO, E.K.; GOEKE, N.M.; OLSON, B.J. and KLENK, D.C. Measurement of protein using bicinchoninic acid. Analytical Biochemistry, October 1985, vol. 150, no. 1, p. 76-85.

TENCZA, S.B.; CREIGHTON, D.J.; YUAN, T.; VOGEL, H.J.; MONTELARO, R.C. and MIETZNER, T.A. Lentivirus-derived antimicrobial peptides: increased potency by sequence engineering and dimerization. The Journal of Antimicrobial Chemotherapy, July 1999, vol. 44, no. 1, p. 33-41.

YOUNT, N.Y. and YEAMAN, M.R. Immunocontinuum: perspectives in antimicrobial peptide mechanisms of action and resistance. Protein and Peptide Letters, January 2005, vol. 12 , no. 1 , p. 49-67.

ZASLOFF, M. Antimicrobial peptides of multicellular organisms. Nature, January 24 2002, vol. 415, no. 6870, p. 389-395.
ZEMEL, A.; BEN-SHAUL, A. and MAY, S. Perturbation of a lipid membrane by amphipathic peptides and its role in pore formation. European Biophysics Journal, May 2005, vol. 34 , no. 3, p. 230-242.

ZHANG, L.; FALLA, T.; WU, M.; FIDAI, S.; BURIAN, J.; KAY, W. and HANCOCK, R.E. Determinants of recombinant production of antimicrobial cationic peptides and creation of peptide variants in bacteria. Biochemical and Biophysical Research Communications, June 29 1998, vol. 247 , no. 3 , p. 674-680. 